\title{
LGBTQ Identity, Nursing Education, and Culturally Safe Care: Suggestions for Educators
}

\author{
Tracey Rickards \\ Faculty of Nursing, University of New Brunswick, Fredericton, NB, Canada \\ srickar1@unb.ca
}

\begin{abstract}
Fifty years have passed since the Stonewall uprising in New York City, signaling the beginning of the modern gay rights movement. Nursing and schools of nursing have a long history of heteronormativity, despite the profession being populated by women who were either members of

religious affiliation or lesbians in hiding. This article explores the historical background of nursing as a profession, the provision of healthcare to LGBTQ individuals, what educators need to include in the curriculum, and finally, several suggestions are provided for educators wondering how to introduce the content.
\end{abstract}

Keywords: Nursing education, LGBTQ patients, Nursing students, Providers

\section{Introduction}

The year 2019 marked 50 years since the Stonewall uprising in New York City, which signaled the birth of the modern gay rights movement [1]. Things have certainly improved, however, we still have work to do before we can say that people are no longer experiencing discrimination on either side of the care relationship. It seems fitting to take a look at nursing education from both the perspective of LGBTQ students and patients. In this article, I will explore the perspectives of LGBTQ students, and patients, and provide suggestions for educators. I will provide suggestions and examples to improve the learning and ultimately patient experience.

I am a nurse, a mother, a wife, and a professor, and I happen to be lesbian. I teach at a university in Atlantic Canada. Every year, for the past 10 years, I have taught a third-year theory course - Community and Population Health, and have had a group of students complete a community-focused clinical practicum associated with the theory course. Several years ago, I also taught fourth-year students in a condensed community practicum completed before beginning the final preceptorship before graduation. I have made it a habit of ensuring that we celebrate the end of clinical by enjoying some social time together. At one of these events, a student told me that she was lesbian and that she had been throughout her time in the nursing program, and would never have disclosed until her program of study was completed. She was concerned about how her classmates would respond to her but worse, she did not want clinical instructors and professors to 'give her a hard time' because she was a lesbian. I was really surprised and deeply saddened by this student's fear of discrimination based on her

Article history:

Received (June 7, 2019), Review Result (September 2, 2019), Accepted (November 21, 2019) 
sexual identity alone. What was more surprising to me was that I had taught her the theory course in her third year and again during this clinical in her fourth year and yet I had not been able to make her feel safe enough to disclose her sexual identity until the end of her program of study.

I am out to students and include LGBTQ content in my course content. I thought that doing so would send a message of acceptance and normalization to the students. I make it explicit that my classroom and community clinical setting are safe spaces, as is my office, in which I display pictures of my family, rainbow flags, safe space stickers, and about a hundred books, all with LGBTQ content! The situation caused me to do some significant self-reflecting about my practice as a nurse and an educator. I considered why this would be happening: What I was doing or not doing? How I could do it differently? What did my faculty need to do differently to convey important messages of acceptance of diversity of all types? How my faculty was or was not supporting my being the only out-lesbian professor? What the faculty was doing to address the gaps in education for nursing students about LGBTQ individuals? I saw the incident with the student as a canary in the mine shaft. Perhaps the situation was worse than I thought. I began to inquire about whether my colleagues were including any LGBTQ content in their courses, and if so, how, and what?

\section{Historical background of the nursing profession}

Nursing has traditionally been a gendered profession, having been influenced by both religious orders and the need for a nursing presence during times of war. The patriarchal and Victorian conservative influences on society [2] are one reason for the emergence of a dominant discourse of the gendered understanding and control of behaviors, of which nursing is one such domain. "Gendered identities are constructed in ways that are both voluntary (i.e. choosing to be a certain way) and [in a] coerced manner" [3]. Social pressures to behave or perform in a certain way are controlled by those in positions of dominant identities, most frequently the patriarchy. Nursing 'grew up' under the guidance of religious orders and within a medical model dominated by a patriarchal healthcare system and society. It has taken many years for nursing to become recognized as its profession, getting away from being the doctor's helper. The dominant discourse that is so familiar in society contributes to the controlling power becoming taken for granted [4]. Internalized beliefs based on the dominant discourse of women being less able or incompetent in comparison to men are one reason why nursing has struggled to establish itself as a profession.

The influence of patriarchy explains most of the early medical research that has been an exploration of the lives and experiences of white males and their reactions to illness and therapy. As an example, our understanding of heart disease was based on male bodies, male physiology, and male reactions to doses of medications. Male dominance has shaped the perspectives of what is right and normal. Dominant discourse controls by preventing those in positions of non-dominance to aspire to positions of power. Heterosexism also can control rigid gender role expectations, another form of the dominant discourse.

Heteronormativity is best defined as the power structure and assumption that heterosexuality is a universal norm, the right and the only way to be in the world [5][6][7], and that anything that deviates from that is consequentially deviant or outside so-called normative parameters [8][9][10][11] We can extrapolate that heteronormativity uses the same principles of dominance to silence and control people living marginalized lives. In 1993 Eliason wrote, "homophobia and heterosexism are not the faults of individual nurses, as they are the legacy of their socialization". 


\section{Providing care to LGBTQ individuals}

People with LGBTQ identity have traditionally been hesitant to disclose their sexual identity to healthcare providers because of experiences of dismissal, abuse, and discrimination [12]. Fear continues to exist for LGBTQ individuals however, the situation is slowly changing. Beagan, Fredericks, and Goldberg [13] completed a study that asked nurses about their thoughts on providing care to LGBTQ patients. They found that nurses in the study did not want to offend, but they were not always sure about how to incorporate sexual identity into the healthcare relationships, nor did they fully comprehend the significance of receiving healthcare as a sexual minority identity [14]. By treating all of their patients in the same way, and believing that sexual identity is not pertinent to the healthcare relationship, these nurses do not acknowledge the social and cultural context of their patients' experiences as members of LGBTQ communities. I surmise that there are many other healthcare professionals treating patients and families in the same manner [14].

Eliason, Dibble, and DeJoseph [15] stated that the stress from societal stigma related to sexuality and gender variations has resulted in higher rates of anxiety, depression, suicide, and substance use among members of LGBTQ communities. I suggest that nursing has tended to paint everyone 'beige' to 'treat everyone the same', thereby denying any cultural differences between people and how these differences contribute to how healthcare interactions are experienced.

Research that explores the preparedness of nurses and other healthcare providers to care for LGBTQ individuals finds that the majority of students lacked sufficient knowledge to be able to provide care [5][8][16][17][18][19][20][21]. These same researchers also frequently found that faculty and educators also felt ill-equipped to teach LGBTQ content.

\section{Educators of LGBTQ content}

Nursing textbooks, up until recently, have not included LGBTQ content; if there was any content, it was generally about gay men, the HIV epidemic, and AIDS. Textbooks tend to be heterosexist by not representing LGBTQ people in examples, case studies, pictures, or illustrations. Nursing scholarship has largely maintained an overwhelming silence concerning LGBTQ health [15]. Nursing has lagged behind other health professions in publishing research, theoretical frameworks, or practice guidelines and in changing policies that address the needs of LGBTQ people. A review of nursing journals by Eliason et al. [15] demonstrated that between 2005 and 2009 there were only eight articles with LGBTQ content published in the top 10 nursing journals. The lack of publications amounts to almost complete silence.

Further to this silence, graduate students and junior faculty who may identify as LGBTQ have reported being discouraged from focusing their programs of research on topics that included LGBTQ issues [22]. Both Dr. Carla Randall and Dr. Michele Eliason were told by superiors that the inclusion of LGBTQ content in their programs of research would make it difficult to publish, challenging to find sources of funding, and could eventually impact the ability to obtain tenure or any kind of job stability [22].

One surprising example of discrimination in healthcare education was the experience of a $\mathrm{Ph}$.D. student who was excited to be starting his graduate program after $30+$ years of nursing. He wanted to focus his studies on LGBTQ health and was a gay man moving to San Francisco, seemingly a perfect situation. He described experiencing the 'triple whammy' of racism as a black man, sexism as a male nurse, and homophobia as a gay man [23]. San Francisco, which is acknowledged as the 'Gay Mecca' was the last place that this student expected to experience such marginalization. 
As a lesbian faculty member, I can concur with some of these findings. While I have not experienced overt heterosexism or homophobia in my faculty, funding for any research about LGBTQ issues has been reviewed with skepticism as to the value of professional knowledge and is extremely difficult to obtain. Many presentation abstracts focused on the health of LGBTQ individuals have not been accepted by medical conference planners, stating that they did not contribute to appropriate bodies of knowledge.

When nursing students read textbooks and listen to lectures that are predominantly heteronormative, the identity of LGBTQ students is denied, resulting in marginalization. But what does marginalization mean? Vasas [24] states that marginalization, as a term, conveys a vague sense of disadvantage and injustice. Hall, Stevens, and Meleis [25] defined marginalization as a process by which individuals and groups are peripheralized based on identity, association, experience, and environment. Marginalization persists because people occupying the center and in the position of holding dominant discourse define and police the margins. The center perpetuates the myths, lies, and labels by creating and recreating the margins because in doing so, they maintain the boundaries of the center and the margins.

Lynam and Cowley [26] explore marginalization as a social determinant of health, stating that the effects of disadvantage are cumulative and that marginalization and social exclusion influence health, most importantly the mental health of people being marginalized. Bordieu et al. [27] cautioned against the insidiousness of marginalization when they said "When marginalization becomes part of the order of things, it deprives one even of the consciousness of exclusion" (p. 153). Marginalization results in consequences for how decisions are made, how resources are distributed and accessed, and how interactions are structured. Perpetuating marginalization conveys messages of 'you do not belong' or 'you are not a person of equal value'. When schools of nursing demonstrate marginalization by relegating discussion of diversity to off-the-cuff side comments rather than including it as a concept of importance, students with alternate sexual identities may feel as if they do not belong or are not valued, which immediately tells them that being there and disclosing sexual identity may put them in difficult, even dangerous, situations.

\section{LGBTQ healthcare providers}

Before women took up the opportunity and/or out of the need to enter the workforce, the only full-time career nurses were nuns, spinsters, and very closeted lesbians [22]. Lesbians who were nurses could, and did, remain single while earning a living. In general, the face of nursing has been white women who subscribe to conservative and Eurocentric norms [15][27]. Educators tend to represent the 'white Anglo-Saxon' majority, as an example especially so in Atlantic Canada, perpetuating the marginalization of minority statuses. Feminist theories have been equated with lesbians, especially 'radical' feminists. In the past, nursing has been understood as women's work, because of this belief suspicion for any men who were nurses was created, perpetuating the ongoing stereotype that male nurses must, therefore, be gay men. The fact that we perpetuate the gender binary by identifying 'the male nurse' as being different from 'the nurse' speaks volumes to a general attitude of heterosexism and refusal to acknowledge anything that deviates from 'normal' [4].

\section{Suggestions for educators}

Given that the format of nursing education has perpetuated challenges with marginalization and a lack of acknowledgment of LGBTQ identity one suggestion is to disrupt traditional nursing education. We should be teaching students to recognize and reflect on systems such 
as dominant discourse which can unconsciously control or influence our thinking. We must include a curriculum that promotes an understanding of the effects of marginalization on members of LGBTQ communities. When schools of nursing do not include LGBTQ content or use textbooks that have little LGBTQ content they convey the message that this content is not important, that a patient's sexual or gender identity does not matter in the healthcare experience, and that students sitting in the classrooms with an LGBTQ identity or who are exploring a sexual minority identity do not matter and do not belong in these classrooms, or this school. Smith [21] stated "for learning beyond tolerance and acceptance to be successfully implemented into a nursing program, faculty must own and promote honor as an intentional area of content for this vulnerable population" (p. 17). Incorporating LGBTQ content, with sensitivity, into examples, scenarios, and lectures convey a message of normalcy and acceptance.

GLMA: Health Professionals Advancing LGBTQ Equality released a report written by Snowdon [28], offering suggestions for making healthcare education a safer place. The report says that it is equally important to include an LGBTQ curriculum to create a welcoming and safe climate for LGBTQ students. It is important to create supportive and inclusive environments that allow students and employees to steer clear of biased and discriminatory behavior and allow students of all identities to become more familiar with diversity and all it encompasses. The report also states that we need to encourage the mentoring of LGBTQ students and staff. Finally, "institutional diversity initiatives can enhance LGBTQ equity and inclusion, sending LGBTQ students and employees the message that they are seen and supported" [28].

I believe that people involved in the education of nurses and other healthcare providers should encourage the exploration of LGBTQ content and support the desire to learn. LGBTQ students should have at their disposal safe spaces to discuss topics related to sex, gender, marginalization, heterosexism, homophobia, and related topics. One way to do it is to use the concept of cultural safety, as it is equally important to create a safe space for the exploration of new ideas as it is to provide opportunities for growth and learning [29]. A vital component of cultural safety is the understanding of the importance of self-reflection. When ideas are presented in the classroom in a respectful way that acknowledges the damaging effects of discrimination, students have a chance to face and address their own biases. Completing the self-reflective process can result in being able to provide holistic and culturally safe care to vulnerable populations. Educators should not expect that we can change the beliefs of students, but that we can open their minds and hearts to understanding the impact of those beliefs and how to provide care while not compromising themselves.

The use of simulation is becoming more familiar in the nursing curriculum. Simulation provides a unique opportunity for nursing students to try intentional interactions with people who identify as lesbian, gay, bisexual, and transgender [30]. Nursing students who engage in simulation experiences, and trial therapeutic interactions without making live patients feel self-conscious about their identity. Nursing and other allied health students need knowledge of what it means to be part of an LGBTQ community and how the specific sex or gender identity affects or influences how healthcare is experienced. There is much research to support the fact that LGBTQ content has accounted for a median of five hours over a fouryear program [16][18][28]. Curricular content such as this cannot be imparted in one session, it must be threaded throughout the curriculum and over the entire length of the program.

In a recent article about making nurse education more LGBTQ-friendly, Pearce [31] stated that research has shown that LGBTQ students have felt pressure to fill the gaps in people's knowledge and curricular content in the classroom. It is unfair to expect LGBTQ students to 
educate their classmates and professors unless they are comfortable with doing so and feel that they are in a safe space. Pearce also stated that academics frequently feel reticent to talk about issues such as sexual orientation and gender identity because of a personal lack of comfort about the topic and a concern for being able to manage the discussion safely and respectfully.

Educators should encourage discussions that seek to better understand how power is structured so that we can begin to unpack and give voice to people whose lives have been spent on the margins for whatever reason and identify alternatives to the power structures that marginalize. Using case studies in the classroom that include LGBTQ individuals such as a gay couple with their adopted child who has appendicitis or a transgender man wondering about the need for cervical cancer screening. Educators can provide readings that focus on the needs of LGBTQ communities, seeking textbooks that include specific scholarly articles that include LGBTQ content. Test questions that include LGBTQ content demonstrate that the content matters to the overall education of care providers. We should be encouraging open and safe discussion to allow students to ask questions that they have been hesitant to or have not asked in the past. It is important to include content that provides accurate information about a full range of sexual variations, avoiding the socially determined binary categories that are entrenched as ideal [32]. Other ways that content can be included are through film, panel discussions, open forums, debates, and the use of books or journal articles focused on LGBTQ health.

It is important to give nursing students opportunities for guided self-reflection encouraging them to consider their own biases and beliefs. Self-reflection can contribute to greater levels of compassion and acceptance of diverse populations [21]. Normalizing sexual diversity in nursing and other allied healthcare classroom settings can improve healthcare and healthcare delivery for both LGBTQ patients and providers.

To increase the inclusion of LGBTQ content in healthcare professional educational programs we need to begin with the educators themselves who may require additional information to gain a greater understanding of what it means to be a member of this sexual and gender minority group. We forget that as educators sometimes we need to gain additional education to provide students with the tools necessary for their learning. Educators have been brought up in a patriarchal society and may hold patriarchal values. Educators need to know how discrimination manifests itself, and how damaging marginalization, homophobia, and heteronormative behavior can be for vulnerable populations. Without this knowledge, it is much more challenging for them to impart the learning to their students. Educators who display strong ally-ship for vulnerable populations, such as LGBTQ people, convey a message of being open to fielding questions and having those sometimes difficult conversations in the process of learning.

\section{Conclusion}

Fifty years after the riot by transgender women of color, fed up with being harassed by police in New York City, we have gained a much greater understanding of the complexities of healthcare that acknowledges the importance of a person's sexual or gender identity. However, we are not yet at a point where we can sit back and watch it all unfold. I will continue to establish safe spaces for student learning opportunities, including case studies, scenarios, and simulations. My wish is that students, in the future, are not afraid of disclosing any marginalized identity. More work is needed to increase LGBTQ content in nursing education, to decrease the discomfort and lack of knowledge by healthcare providers in 
providing care to LGBTQ individuals, and to increase the safety of students in healthcare professions who themselves identify as LGBTQ individual.

\section{References}

[1] Field N., "They've lost that wounded look: Stonewall and the struggle for LGBT+ rights," Critical and Radical Social Work, vol.6, no.1, pp.35-50, (2018) DOI:10.1332/204986018X15199226335132

[2] M. Foucault, "The history of sexuality," vol.1, An Introduction, New York, NY: Vintage Press, (1990)

[3] L. Zak-Hunter, L. E. Marshall, A. L. Arnold, S. Consiglio, J. Gale, C. Liddy, and D. P. Magwitz-Greyson, "Finding our voices in the face of dominant discourse: A closer look at gendered roles' impact on student clinicians," Journal of Feminist Family Therapy, vol.22, pp.187-202, (2010) DOI: 10.1080/08952833.2010.499701

[4] M. Eliason, "The gender binary in nursing," Nursing Inquiry, vol.24, (2017) DOI: 10.1111/nin.12176

[5] G. Röndahl, "Students' inadequate knowledge about lesbian, gay, bisexual and transgender persons," International Journal of Nursing Education Scholarship, vol.6, Article no.11, (2009) DOI:10.2202/1548923X.1718

[6] T.Wilton, "Sexualities in health and social care - A textbook," Philadelphia, PA: Open University Press, (2000)

[7] G. Yep, "The violence of heteronormativity in communication studies: Notes on injury, healing, and queer world-making," Journal of Homosexuality, vol.45, pp.11-59, (2003)

[8] F. A. Lim, M. Johnson, and M. Eliason, "A national survey of faculty knowledge, experience, and readiness for teaching lesbian, gay, bisexual, and transgender health in baccalaureate nursing programs," Nursing Education Perspectives, vol.36, pp.144-152, (2015) DOI: 10.5480/14-1355

[9] S. Morrison and S. Dinkel, "Heterosexism in health care: A concept analysis," Nursing Forum, vol.47, pp.123-130, (2012) DOI: 10.1111/j.1744-6198.2011.00243.x

[10] T. Rickards, and D. McLeod, "Authenticating family: A grounded theory explaining the process of re/claiming legitimacy by lesbian stepfamilies," The Family Journal: Counseling and Therapy for Couples and Families, vol.24, pp.122-131, (2016) DOI:10.1177/1066480716628583

[11] G. Röndahl, S. Innala, and M. Carlsson, "Heterosexual assumptions in verbal and non-verbal communication in nursing," Journal of Advanced Nursing, vol.56, pp.373-381, (2006) DOI:10.1111/j.13652648.2006.04.18.x

[12] K. Rossman, P. Salamanca, and K. Macapagal, "The doctor said I didn't look gay!: Young adults' experiences of disclosure and nondisclosure of LGBTQ identity to health care providers," Journal of Homosexuality, vol.64, pp.1390-1410, (2017) DOI: 10.1080/00918369.2017.1321379

[13] B. L. Beagan, E. Fredericks, and L. Goldberg, "Nurses' work with LGBTQ patients: "They're just like everybody else, so what's the difference?", 'Canadian Journal of Nursing Research, vol.44, pp.44-63, (2012)

[14] M. Eliason, S. Dibble, and J. DeJoseph, "Nursing's silence on lesbian, gay, bisexual, and transgender issues: The need for emancipatory efforts," Advances in Nursing Science, vol.33, pp.206-218, (2010) DOI: 10.1097/ANS.0b013e3181e63e49

[15] M. R. Bleich, B. R. MacWilliams, and B. J. Schmidt, "Advancing diversity through inclusive excellence in nursing education," Journal of Professional Nursing, vol.31, pp.89-94, (2015) DOI: 10.1016/j.profnurs.2014.09.003

[16] H. M. Braun, D. Ramirez, G. J. Zahner, E. M. Gillis-Buck, H. Sheriff, and M. Ferrone, "The LGBTQI health forum: An innovative interprofessional initiative to support curriculum reform," Medical Education Online, vol.22, (2017) DOI: 10.1080/10872981.2017.1306419

[17] M. Caboral-Stevens, M. Rasoria-Sim, and K. Lovence, "Cultural competence in nursing faculty of the LGBT population," International Journal of Nursing \& Care, vol.2, (2018) 
[18] A. Daley, and J. A. MacDonnell, " That would have been beneficial': LGBTQ education for home-care service providers," Health and Social Care in the Community, vol.23, pp.282-291, (2015) DOI: $10.1111 / \mathrm{hsc} .12141$

[19] C. Echezona-Johnson, "Evaluation of lesbian, gay, bisexual, and transgender knowledge in basic obstetrical nursing education," Nursing Education Perspectives Online, vol.38, pp.138-142, (2017) DOI: 10.1097/01.NEP. 0000000000000136

[20] P. S. Smith, "Cultural safety in nursing education: Increasing care for LGBT individuals," Unpublished master's thesis, Washington State University, Spokane, WA, (2010)

[21] C. Randall, and M. Eliason, "Out lesbians in nursing: What would Florence say?" Journal of Lesbian Studies, vol.16, pp.65-75, (2012) DOI:10.1080/10894160.2011.557644

[22] J. Turner, "Sexual orientation and gender identity in nursing," Minority Nurse, June, Retrieved from https://minoritynurse.com/sexual-orientation-and-gender-identity-in-nursing, (2014)

[23] E. B. Vasas, "Examining the margins: A concept analysis of marginalization," Advances in Nursing Science, vol.28, pp.194-202, (2005)

[24] J. M. Hall, P. E. Stevens, and A. I. Meleis, "Marginalization: A guiding concept for valuing diversity in nursing knowledge development," Advances in Nursing Science, vol.16, pp.23-41, (1994)

[25] J. M. Lynam and S. Cowley, "Understanding marginalization as a social determinant of health," Critical Public Health, vol.17, pp.137-149, (2007)

[26] P. Bourdieu, A. Accardo, G. Balacs, S. Beaud, F. Bonvin, and E. Bourdieu, "The weight of the world: Social suffering in contemporary society," Cambridge: Policy Press

[27] T. Leonard, "Exploring diversity in nursing education: Research findings," Journal of Cultural Diversity, vol.13, pp.87-94, (2006)

[28] S. Snowdon, "Recommendations for enhancing the climate for LGBT students and employees in health professional schools: A GLMA white paper," Washington, DC: GLMA, (2013)

[29] F. Hart-Wasekeesikaw, "Cultural competence and cultural safety in nursing education: A framework for the first nation, inuit, and metis nursing," Ottawa, ON: Aboriginal Nurses Association of Canada Retrieved from: https://www.cna-aiic.ca/ /media/cna/page-content/pdf-en/first_nations_framework_e.pdf, (2009)

[30] A. T. Maruca, D. A. Diaz, C. Stockman, and L. Gonzalez, "Using simulation with nursing students to promote affirmative practice toward the lesbian, gay, bisexual, and transgender population: A multisite study," Nursing Education Perspectives, vol.39, pp.225-229, (2018) DOI:10.1097/01.NEP. 000000000000302

[31] L. Pearce, "Making nurse education LGBT-friendly," Nursing Standard, vol.31, pp.23-24, (2017)

[32] E. M. Saewyc, "Respecting variations in the embodiment as well as gender: Beyond the presumed 'binary' of sex,” Nursing Inquiry, vol.24, (2017) DOI: 10.1111/nin.12184

\section{Author}

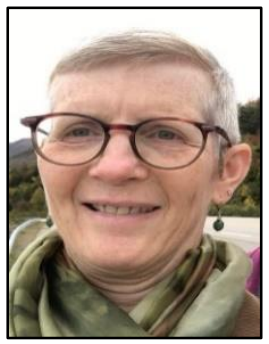

\section{Dr. Tracey Rickards}

Dr. Rickards is an Associate Professor at the Faculty of Nursing at the University of New Brunswick, Fredericton Campus. She has always been an advocate for LGBTQ rights and has included LGBTQ content in her teaching. She holds a CIHR four-year Embedded Clinician Researcher Award. 